Electronic Physician (ISSN: 2008-5842)

http://www.ephysician.ir

February 2016, Volume: 8, Issue: 2, Pages: 2039-2047, DOI: http://dx.doi.org/10.19082/2039

\title{
Immunosuppressive therapy in children with steroid-resistant, frequently-relapsing, and steroid- dependent idiopathic nephrotic syndrome: a single center experience
}

\author{
Bahia Hassan Moustafa ${ }^{1}$, Omar Atef Tolba $^{2}$
}

${ }^{1}$ MD., Professor of Pediatrics and Pediatric Nephrology, Department of Pediatrics, Cairo University, Egypt
${ }^{2}$ Ph.D., Assistant Consultant of Pediatrics, Cairo University Children's Hospital, Department of Pediatrics, Cairo
University, Egypt

Type of article: Original

\begin{abstract}
Introduction: Immunosuppressive agents are recommended for the management of children with steroidresistant (SRNS), frequently-relapsing (FRNS), and steroid-dependent idiopathic nephrotic syndrome (SDNS). This study evaluated the efficacy of immunosuppressive agents in these cases.

Methods: This is a retrospective analysis of the records of 130 pediatric cases recruited from a tertiary-care center over a period of two years. They were divided into two groups: 51 patients with SRNS (Group I) and 79 cases with SDNS and FRNS (Group II). They were treated with immunosuppressive agents in addition to steroids, either as double- or triple-combination therapy. Complete or partial remission was considered a good response.

Results: In group I, the proportions of good response to cyclophosphamide, cyclosporine A, and mycophenolate mofetil were $48.6,60$, and $80 \%$, respectively $(\mathrm{p}=0.162)$. In group II, the resistance rate was significantly higher with levamisole than with cyclophosphamide and azathioprine $(p=0.046)$. Leukopenia was reported infrequently after the administration of cyclophosphamide or azathioprine. The most serious adverse reaction was to cyclosporine A, which induced nephrotoxicity $(6.4 \%)$, while no adverse effects related to levamisole were reported. Histopathological diagnoses were available in only 39 patients.

Conclusion: The high potency of cyclosporine with steroids recommends its use in patients with idiopathic SRNS with a normal glomerular filtration rate. Its efficacy is augmented when combined with mycophenolate mofetil. Cyclophosphamide, orally or as intravenous boluses, together with alternate-day steroids, could be a good option outside the peripubertal age. The outcomes of FRNS and SDNS could be improved by encouraging compliance with the use of levamisole.
\end{abstract}

Keywords: childhood nephrotic syndrome, steroid resistance, steroid dependence, relapse, immunosuppressant

\section{Introduction}

Idiopathic nephrotic syndrome (INS) is defined by altered permselectivity of the glomerular filter associated with non-specific histological abnormalities of the kidney $(1,2)$. It is the most common type of nephrotic syndrome (NS) in children worldwide as compared to hereditary or secondary types. Its incidence in Egypt is $88 \%$ among nephrotic children, where minimal change nephrotic syndrome (MCNS) is the most prevalent variant followed by focal segmental glomerulosclerosis (FSGS) and mesangioproliferative glomerulonephritis (MesPGN) (3). Corticosteroids are the mainstay of treatment; more than $90 \%$ of children with INS are steroid sensitive (SSNS) and respond to therapy with remission of proteinuria. Unfortunately, INS follows a relapsing and remitting course in the majority, with $90 \%$ relapsing at least once, and up to $60 \%$ will progress to frequently relapsing nephrotic syndrome (FRNS) or steroid-dependent nephrotic syndrome (SDNS). Approximately $10-20 \%$ of children with NS will not respond to therapy with corticosteroids and are classified as steroid-resistant (SRNS) (2, 4-6). The underlying histopathology usually affects the course of the disease and the response to treatment (7). MCNS is the main pediatric form of INS

\section{Corresponding author:}

Dr. Omar Atef Tolba, Department of Pediatrics, Cairo University, Egypt.

Tel: +20.1222101717,+20.233025539, Fax:+20.233025539, E-mail: omartolba80@yahoo.com

Received: December 03, 2015, Accepted: February 02, 2016, Published: February 2016

iThenticate screening: February 02, 2016, English editing: February 05, 2016, Quality control: February 08, 2016

(C) 2016 The Authors. This is an open access article under the terms of the Creative Commons Attribution-NonCommercialNoDerivs License, which permits use and distribution in any medium, provided the original work is properly cited, the use is non-commercial and no modifications or adaptations are made. 
and is usually a benign condition responsive to standard steroids treatment $(6,8)$. Several reports have been published on the changing trends in the histopathology of NS toward the increasing incidence of FSGS in children $(7,9,10)$. Those changes are accompanied by an increase in steroid resistance, as FSGS seems to be strongly related to poor response to corticosteroid therapy with the majority of cases evolving to terminal renal insufficiency within several years $(8,11)$. Management of these patients who fail to show a remission with steroids (steroid-resistant), those who fail to have a long remission (frequently relapsing), and those who cannot be weaned from steroids (steroid-dependent), is difficult since they are at risk for complications of unremitting nephrotic syndrome and progressive renal disease and at risk of the effects of treatment with immunosuppressive medications or long-term steroid use (12). Hence, a rescue therapy in difficult cases of INS is needed in order to avoid unnecessary exposure to toxic drugs. Currently, an optimal combination of immunosuppressive agents to induce remission and to reduce the undesirable effects of high dose and prolonged administration of drugs is still a challenge (13, 14). The aim of this study was to evaluate the efficacy of immunosuppressive agents in steroid-resistant, frequently-relapsing, and steroid-dependent nephrotic syndrome in children.

\section{Material and Methods}

\subsection{Study Design and population}

This was a retrospective analysis of the records of children presented over a period of two years, from June 2012 to June 2014, to the pediatric nephrology outpatient clinic at Cairo University Children's Hospital (CUCH), which is the main tertiary referral center for pediatric nephrology in Egypt. The study was approved by the local Ethics Committee. Informed parental consent was obtained prior to enrolling the children in the study. The study included 130 children having INS with steroid-resistant, steroid-dependent, and frequently-relapsing subtypes, for which they received immunosuppressive treatment. Their age at onset of the disease was more than one and less than 16 , and they were followed up regularly for two years. Patients with incomplete records, secondary nephrotic syndrome, and congenital or syndromic forms were excluded. The cases were categorized into two groups: Group I, which comprised 51 cases with SRNS, and Group II, which comprised 79 cases with SDNS and FRNS.

\subsection{Data collection}

The data collected included basic demographic, clinical and laboratory data at initial presentation (age at onset; birth date; gender; weight; height; blood pressure; urine analysis, 24-hour urine protein excretion, complete blood count, serum levels of urea, creatinine, cholesterol, albumin, C3 and C4). Histopathological findings of renal biopsy were recorded. Follow-up data of the progress of the disease were recorded, including remissions or relapses and complications of INS and corticosteroid therapy. Responses to immunosuppressive therapy and their adverse effects were recorded.

\subsection{Definitions}

The terms used for NS definitions, treatment, and its responses as per the unit protocol were as follows: Nephrotic syndrome comprises heavy proteinuria exceeding $50 \mathrm{mg} / \mathrm{kg} /$ day or urine albumin/creatinine ratio $>2$, hypoalbuminemia $<2.5 \mathrm{~g} / \mathrm{dL}$, hypercholesterolemia, and edema (15). Complete remission was defined as the presence of trace or negative proteinuria on the dipstick method for three consecutive early morning specimens. Partial remission was defined as absence of edema, serum albumin $>2.5 \mathrm{~g} / \mathrm{dL}$, and a proteinuria of $1+$ or $2+$ on the dipstick method. Resistance was defined as 3-4+ proteinuria, serum albumin $<2.5 \mathrm{~g} / \mathrm{dL}$, or edema (2, 16). Steroid dependence was defined when there were two consecutive relapses while on alternate day steroids or within 14 days of their discontinuation. Frequent relapses were defined by two or more relapses in six months or more than three relapses in any 12 months $(2,16)$. Steroid resistance was defined as failure to achieve remission despite daily therapy with oral prednisone at a dose of $2 \mathrm{mg} / \mathrm{kg} /$ day for eight weeks or on oral prednisone for four weeks followed by three pulses intravenous methylprednisolone (17). Failure of alternative medication was defined when a patient failed to maintain a long remission for a minimum of six months; had two or more relapses over six months while on treatment with any of these agents, its replacement with an alternative medication should be considered. Cyclophosphamide resistance was defined as a failure to achieve complete or partial remission after 8-12 weeks of treatment at the dosage of $2-2.5 \mathrm{mg} / \mathrm{k} / \mathrm{d}$. Cyclosporine A resistance was defined as the failure to achieve partial or complete remission after three months of treatment (18). Levamisole was considered ineffective and stopped if the child failed to maintain remission for six months or developed two or more relapses while on levamisole and every other day steroids or when steroids could not be totally withdrawn (19). 


\subsection{Renal biopsy}

Histopathological diagnoses were available in only 39 patients. Indications for renal biopsy were SRNS $(\mathrm{n}=31$ ), SDNS $(n=7)$, and FRNS $(n=1)$. Of the biopsied patients, the age at onset of the disease was $>10$ years in two children; four children had a positive family history, and two children were hypertensive. Renal biopsy was justified in all SRNS cases, while it was done in FRNS and SDNS cases on an individual basis considering its risk/benefit value or prior to the introduction of cyclosporine A therapy, as per unit plan. Parental consent was obtained for all cases prior to the procedure.

\subsection{Immunosuppressive therapy}

In the current study, achieving a complete or partial remission after treatment was considered a good response (20, 21). In addition to steroids, patients were treated with one or more of the following immunosuppressive agents: cyclophosphamide (CPO) cyclosporine A (CsA), mycophenolate mofetil (MMF), azathioprine (Aza), and levamisole (Leva). They were given in either double- or triple-combination therapy. In group I, CPO was used as first line treatment in 33 patients and second line in two patients (six patients were biopsied and 29 refused); CsA was used as a first line in 18 patients and as second-line in seven (all 25 patients were biopsied); MMF was added to the treatment regimen in 10 patients who were resistant to CsA. In group II, CPO was used as first line treatment in 25 patients and second or third line in three patients; CsA was used as first line treatment in four cases and as second or third line in two patients; MMF was used as first line in two cases; azathioprine was used as a first line in eight cases and second or third line in two cases; levamisole was used as first line in 40 patients. CPO was given per oral (PO) with a dose of 2-3 mg/ $/ \mathrm{kg} /$ day for $8-12$ weeks, or intravenously as a monthly bolus of $500-750 / \mathrm{m}^{2}$ for six months. CsA was given PO with a dose of $4-6 \mathrm{mg} / \mathrm{kg} /$ day for a minimum of 12 months. MMF was given PO with a dose of $1200 \mathrm{mg} / \mathrm{m}^{2} /$ day in two divided doses. Azathioprine was administered PO as a single daily dose of $2 \mathrm{mg} / \mathrm{kg}$ for eight weeks. Levamisole was given PO at a dose of 2-2.5 mg/kg/dose twice weekly for 6-24 months.

\subsection{Statistical analysis}

The data were analyzed using IBM SPSS Advanced Statistics, version 22.0 (IBMC Corp., Armonk, NY, USA). Numerical data were expressed as mean, standard deviation, and range. Qualitative data were expressed as frequency and percentage. The chi-squared test (Fisher's exact test) was used to examine the relationship between the qualitative variables. For quantitative data, the two groups were compared using the Mann-Whitney test.

\section{Results}

The demographic, clinical, and laboratory characteristics of the study population at the time of initial presentation are provided in Table 1. As shown in Table 2, the two groups were comparable regarding age at initial presentation $(p=0.614)$, age at onset $(p=0.391)$, gender $(p=0.336)$, positive family history $(p=0.1000)$, and gross hematuria $(p=0.152)$. Group I showed a significantly higher frequency of hypertension $(p=0.014)$, hypocomplementemia, and impaired kidney functions $(\mathrm{p}<0.001)$.

Table 1. Demographic, clinical, and laboratory characteristics at initial presentation of the study population

\begin{tabular}{|c|c|c|}
\hline \multicolumn{2}{|l|}{ Variables } & Findings \\
\hline \multicolumn{2}{|l|}{ Age at initial presentation (year) } & $4.3(2.0-14.0)$ \\
\hline \multicolumn{2}{|l|}{ Gender ratio (Male/Female) } & $68 / 62(1.1: 1.0)$ \\
\hline \multicolumn{2}{|l|}{ Age at onset (year) } & $3.9(1.2-12.0)$ \\
\hline \multicolumn{2}{|l|}{ Positive family history; $\mathrm{n}(\%)$} & $4(3.1)$ \\
\hline \multirow[t]{2}{*}{ Body weight percentile; n (\%) } & $<5^{\text {th }}$ centile & $5(3.8)$ \\
\hline & $>95^{\text {th }}$ centile & $7(5.4)$ \\
\hline \multicolumn{2}{|l|}{ Hemoglobin, gm/dL } & $12.0 \pm 1.2$ \\
\hline \multicolumn{2}{|l|}{ Blood urea, mg/dL } & $34.5(8.0-140.0)$ \\
\hline \multicolumn{2}{|l|}{ Serum creatinine, $\mathrm{mg} / \mathrm{dL}$} & $0.7(0.1-2.6)$ \\
\hline \multicolumn{2}{|l|}{ Serum albumin, $\mathrm{g} / \mathrm{dL}$} & $1.5(0.4-2.5)$ \\
\hline \multicolumn{2}{|l|}{ Urine albumin/creatinine ratio } & $4.6(0.6-52.2)$ \\
\hline \multicolumn{2}{|l|}{ Serum cholesterol, mg/dL } & $430(210-913)$ \\
\hline \multicolumn{2}{|l|}{$\mathrm{C}_{3}, \mathrm{mg} / \mathrm{dL}$} & $110(20-180)$ \\
\hline \multicolumn{2}{|l|}{$\mathrm{C}_{4}, \mathrm{mg} / \mathrm{dL}$} & $29(8-96)$ \\
\hline
\end{tabular}


Table 2. Comparison between the characteristics of the studied groups at initial presentation

\begin{tabular}{|l|l|l|l|l|}
\hline Variables & Group I $(n=51)$ & Group II $(n=79)$ & Test value & $p$-value \\
\hline Age at initial presentation (year) & $5.2(2.0-14.0)$ & $5.0(2.3-12.0)$ & 0.506 & $0.614^{\dagger}$ \\
\hline Age at onset (year) & $4.1(1.1-12.0)$ & $3.7(1.3-10.5)$ & 0.861 & $0.391^{\dagger}$ \\
\hline Gender ratio (Male/Female) & $24 / 27$ & $44 / 35$ & 0.927 & 0.336 \\
\hline Positive family history & 1 & $3(3.8)$ & $*$ & 1.000 \\
\hline Hypertension & $24(47.1)$ & $6(7.6)$ & 6.050 & 0.014 \\
\hline Gross hematuria & $2(3.9)$ & 0 & $*$ & 0.152 \\
\hline Hypocomplementemia & $21(41.2)$ & $3(3.8)$ & 28.766 & $<0.001$ \\
\hline Impaired Kidney functions & $22(43.1)$ & $3(3.8)$ & 30.880 & $<0.001$ \\
\hline
\end{tabular}

Data are expressed as median (range), frequency (\%) or ratio. Analysis by: Chi-square test; ${ }^{\dagger}$ Mann-Whitney test; *Fisher's exact test

The most frequent histopathological diagnosis for all cases was FSGS and MCNS in 15 cases (38.5\%) of each. The median age at onset of the disease is shown in Table 3. Age at onset was comparable in children with FSGS and MCNS ( $p=0.217)$. In group I, the most frequent pathological diagnosis was FSGS in $14(45.2 \%)$ followed by MCNS in $10(32.2 \%)$, while, among group II, it was MCNS in $5(62.5 \%)$ (Table 4). The complications of the disease and/or steroid therapy during follow-up are shown in Table 5.

Table 3. Histopathological diagnosis of biopsied children and its relationship to the median age at onset

\begin{tabular}{|l|l|l|}
\hline Pathological Diagnosis & $\mathrm{n}(\%)$ & Age at onset (months) \\
\hline Minimal change nephrotic syndrome & $15(38.5)$ & $48(13-84)$ \\
\hline Focal segmental glomerulosclerosis & $15(38.5)$ & $50(15-92)$ \\
\hline Mesangioproliferative glomerulonephritis & $4(10.2)$ & $36(12-75)$ \\
\hline Membranoproliferative glomerulonephritis & $4(10.2)$ & $60(16-144)$ \\
\hline Membranous glomerulonephritis & $1(2.6)$ & 65 months \\
\hline
\end{tabular}

Table 4. Histopathological pattern in the studied groups $(n=39)$

\begin{tabular}{|l|l|l|}
\hline Pathological diagnosis & Group I $(\mathrm{n}=31) ; \mathrm{n}(\%)$ & Group II $(\mathrm{n}=38) ; \mathrm{n}(\%)$ \\
\hline Minimal change nephrotic syndrome & $10(32.2)$ & $5(62.5)$ \\
\hline Focal segmental glomerulosclerosis & $14(45.2)$ & $1(12.5)$ \\
\hline Mesangioproliferative glomerulonephritis & $3(9.7)$ & $1(12.5)$ \\
\hline Membranoproliferative glomerulonephritis & $3(9.7)$ & $1(12.5)$ \\
\hline Membranous glomerulonephritis & $1(3.2)$ & $0(0.0)$ \\
\hline
\end{tabular}

Data are expressed as frequency (\%).

Table 5. Complications of idiopathic nephrotic syndrome and/or steroid therapy among the study population during follow-up of the disease

\begin{tabular}{|l|l|l|}
\hline Variable & $\mathrm{n}$ & $\%$ \\
\hline Cushingoid facies & 130 & 100 \\
\hline Infections & 70 & 53.8 \\
\hline Hypertension & 68 & 52.3 \\
\hline Gastric irritation & 11 & 8.5 \\
\hline Overweight & 8 & 6.1 \\
\hline Hyperglycemia & 6 & 4.6 \\
\hline Growth retardation & 5 & 3.8 \\
\hline Hypertensive encephalopathy & 2 & 1.5 \\
\hline Hypertensive retinopathy & 1 & 0.8 \\
\hline Acute renal failure & 2 & 1.5 \\
\hline Chronic renal failure & 1 & 0.8 \\
\hline Intracranial hemorrhage & 1 & 0.8 \\
\hline Extensive subclavian vein thrombosis & 1 & 0.8 \\
\hline
\end{tabular}


Apart from cushingoid facies, the most frequent complications were infections (53.8\%) and hypertension (52.3\%). The most frequently used immunosuppressive agent (either as first or second line treatment) in group I was CPO in 35 (68.6\%), followed by CsA in $25(49 \%)$ and MMF in $10(19.6 \%)$; while in group II, levamisole was used in 40 patients (50.6\%), followed by CPO in 28 (35.4\%), and azathioprine in 10 (12.7\%) (Table 6). Among SRNS patients, the difference in response to the three drugs used was statistically non-significant $(\mathrm{p}=0.162)$ (Table 7). In group II, a significantly higher resistance to treatment was found among levamisole users compared to the other drugs $(\mathrm{p}=$ 0.046) (Table 8). Adverse effects related to each of the immunosuppressive drugs used in the study are summarized in Table 9. No adverse effects related to levamisole were reported.

Table 6. Frequency of use of immunosuppressive agents in the studied groups*

\begin{tabular}{|l|l|l|}
\hline Drug & Group I; $\mathbf{n}(\%)$ & Group II; $\mathbf{n}(\%)$ \\
\hline Cyclophosphamide & $35(68.6)$ & $28(35.4)$ \\
\hline Cyclosporine A & $25(49.0)$ & $6(7.6)$ \\
\hline Mycophenolatemofetil & $10(19.6)$ & $2(2.5)$ \\
\hline Azathioprine & $0(0.0)$ & $10(12.7)$ \\
\hline Levamisole & $0(0.0)$ & $40(50.6)$ \\
\hline
\end{tabular}

Data are expressed as frequency (\%). ${ }^{*}$ Numbers of cases receiving the drug as first or second line are expressed.

Table 7. Response to treatment among steroid-resistant nephrotic patients*

\begin{tabular}{|l|l|l|l|l|}
\hline \multirow{2}{*}{ Patient response } & CPO & CsA & MMF & \multirow{2}{*}{$p$-value } \\
\cline { 2 - 5 } & $(n=35)$ & $(n=25)$ & $(n=10)$ & \\
\hline Complete and partial remission & $17(48.6)$ & $15(60.0)$ & $8(80.0)$ & \multirow{2}{*}{0.162} \\
\hline Resistance & $18(51.4)$ & $10(40.0)$ & $2(20.0)$ & \\
\hline
\end{tabular}

Data are expressed as frequency (\%). ${ }^{*}$ Numbers of cases receiving the drug as first or second line are expressed. Analysis by: Chi-square test. CPO: cyclophosphamide; CsA: cyclosporine A; MMF: Mycophenolatemofetil.

Table 8. Response to treatment among steroid-dependent and frequently relapsing nephrotic patients*

\begin{tabular}{|l|l|l|l|l|l|l|}
\hline Patient response & CPO & CsA & MMF & Aza & Leva & \multirow{2}{*}{$p$-value } \\
\cline { 2 - 7 } & $(n=28)$ & $(n=6)$ & $(n=2)$ & $(n=10)$ & $(n=40)$ & \\
\hline Long remission (6 months) & $24(85.7)$ & $5(83.3)$ & $1(50.0)$ & $8(80.0)$ & $22(55.0)$ & 0.046 \\
\hline Resistance & $4(14.3)$ & $1(16.7)$ & $1(50.0)$ & $2(20.0)$ & $18(45.0)$ & \\
\hline
\end{tabular}

Data are expressed as frequency (\%). ${ }^{*}$ Numbers of cases receiving the drug as first or second line are expressed.

Analysis by: Fisher's exact test. CPO: cyclophosphamide; CsA: cyclosporine A; MMF: Mycophenolatemofetil; Aza: azathioprine; Leva: Levamisole.

Table 9. Adverse effects related to immunosuppressive drugs

\begin{tabular}{|c|c|c|c|c|}
\hline Drug & Side effect & $\mathrm{n}$ & $\%$ & Total $(\%)$ \\
\hline \multirow[t]{2}{*}{ Cyclophosphamide $(n=63)$} & Leukopenia & 15 & 23.8 & \multirow{2}{*}{$17(27)$} \\
\hline & Hemorrhagic cystitis & 2 & 3.2 & \\
\hline \multirow[t]{4}{*}{ Cyclosporine $\mathrm{A}(n=31)$} & Gum hyperplasia & 8 & 25.8 & \multirow[t]{4}{*}{$19(61.2)$} \\
\hline & Hirsutism & 7 & 22.6 & \\
\hline & Nephrotoxicity & 2 & 6.4 & \\
\hline & Hypertension & 2 & 6.4 & \\
\hline \multirow[t]{4}{*}{ Mycophenolatemofetil $(n=12)$} & Diarrhea & 7 & 58.4 & \multirow[t]{4}{*}{$12(100)$} \\
\hline & Nausea & 3 & 25.0 & \\
\hline & Abdominal pain & 1 & 8.3 & \\
\hline & Cough & 1 & 8.3 & \\
\hline \multirow[t]{4}{*}{ Azathioprine $(n=10)$} & Leukopenia & 2 & 20.0 & \multirow[t]{4}{*}{$7(70)$} \\
\hline & Diarrhea & 2 & 20.0 & \\
\hline & Abdominal pain & 2 & 20.0 & \\
\hline & Arthralgia & 1 & 10.0 & \\
\hline
\end{tabular}

Data are expressed as frequency and percentage (\%). 


\section{Discussion}

Traditional and newly-developed immunosuppressive agents used in pediatric NS represent a rich area of research for many authors worldwide. The guidelines of the International Study of Kidney Diseases in Children (ISKDC) are changing in quest of higher potency and less side effects. This work demonstrates the experience of our center regarding their use in the treatment of SRNS, FRNS, and SDNS. In SRNS cases (group I), the most frequent histopathologic subtypes were FSGS in 45.2\% and MCNS in 32.2\%; MesPGN and MPGN in 9.7\% for each; and MGN in 3.2\%. The immunosuppressive agents that were used either as the first or second line treatment were CPO in $68.6 \%, \mathrm{CsA}$ in $49 \%$, and MMF in $19.6 \%$. CsA was used as the first-line drug in 18 patients and as the second-line drug in seven patients. The age range of the 18 patients was $10-14$, and 14 of them had FSGS. Higher gonadal toxicity anticipated in this peripubertal age, as well as the high probabilities of drug resistance in FSGS may explain its choice as the first-line drug despite its side effects, which include nephrotoxicity and dependence. CsA achieved a $60 \%$ remission rate that was further augmented with the addition of MMF to $80 \%$. This was higher than the previous reports: Brandis et al. reported a remission rate of $20 \%$ for CsA with higher efficiency when combined with steroids (24\% versus 14\%) (22); another French study reported a 48\% remission rate (23). The present study reported an $80 \%$ remission rate for MMF combined with CsA and low-dose prednisone in 10 cases of SRNS, in whom CsA proved failure after three months. Similarly, a 70\% remission rate was reported recently by Echeversi and colleagues (24). MMF is not recommended for sole use in steroid-resistant cases; it was reported to induce the reduction of proteinuria with partial remission (21). However, Ulinski et al. reported a 50\% remission rate in 2005 (25). More recent studies have reported positive results with decrease in relapse rate, less proteinuria, and steroidsparing dose without any nephrotoxic effect. It was approved by FDA in 1995 for use in pediatric renal transplantation, SRNS, and SDNS $(24,26)$. CPO was used more commonly in the SRNS group (68.6\%), mainly as a first-line treatment. The age range for the 35 patients was 2.3-8, and the prevalent pathology in the six biopsied cases was MCNS in four cases and MesPGN in two cases. Despite the small number of cases that accepted biopsy, it was used due to its less adverse effects compared to CsA. In the current study, the remission rate after CPO was $48.6 \%$; it was used mainly through the oral route; and as intravenous six-pulse doses in only two cases. Kari and Halawani (2010) reported a 25\% remission rate in steroid-resistant cases treated with CPO (27). Siegel et al. reported a $50 \%$ remission rate in children with MCNS, who changed to be steroid sensitive in their future relapse (28). Other authors have reported CPO failure in inducing remission (29, 30). Also, intravenous pulse CPO proved superior to oral CPO (31), especially when combined with steroids. In FRNS and SDNS cases (Group II), renal histopathology of the eight cases were MCNS $(n=5,62.5 \%)$ and one case each of FSGS, MesPGN, and MGN. Levamisole was the most frequently used drug (50.6\%) followed by CPO (35.4\%) and azathioprine (12.7\%); CsA (7.6\%) and MMF (2.5\%) were rarely used in this center for steroid-dependent cases. Levamisole treatment resulted in reducing relapse rate in 55\% of cases; it maintained six-month remission after a relapse. Madani et al. evaluated the efficacy of levamisole among 304 children and demonstrated that it was effective in children with both SDNS and FRNS, in line with the current study as the relapse rates were reduced by about one-half (32). Ekambaram et al. (2014) found that it was effective in prolonging remission and reducing relapse rate in $77.3 \%$ of SDNS and $80.6 \%$ of FRNS in India (19). Being potent and steroid-sparing, cheap, palatable, and with few side effects even when taken for years, makes it the most recommended first-line drug for frequently relapsing and steroid-dependent cases. Drug discontinuation is soon followed by a relapse (British Association Study)(33). Hence, the reduced efficacy in our study could be explained by the limited availability of the drug leading to suboptimal adherence to treatment.

In the present study, CPO treatment resulted in a six-month long remission rate of $85.7 \%$. Its efficacy was previously reported $(34,35)$, and it is recommended to be combined with steroids (35). Also, a 12-week course was preferred over the 8-week course (two-year relapsing rate of $67 \%$ versus $22 \%$, respectively) (36). Some studies reported that CPO is less effective in SDNS than FRNS (37). Chen et al. reported a prolonged remission in $72 \%$ of children with SDNS (35). Azathioprine was associated with an 80\% six-month long remission rate, which was similar to CPO and CsA. In fact, most controlled studies of children with FRNS or SDNS showed that azathioprine does not reduce the number of children who relapse before 6 months significantly compared to steroids or placebo control groups (38). MMF use in idiopathic SDNS is still questionable, but it was recommended by Echeverri et al. as it reduced the frequency of relapses with reduction of steroid doses without deterioration of the glomerular filtration rate (24). However, in the present study, only two cases received MMF because of the limited experience with the use of this drug in children. The restricted use of CsA and MMF in this unit in FRNS or SDNS compared to levamisole and CPO was attributed to being steroid-sparing with relatively low side effects as well as the high potency of this combination in reducing relapse rates. 
In general, apart from steroid complications, the most prevalent adverse reactions of the immunosuppressive drugs were those reported for MMF and azathioprine. However MMF's adverse reactions were not serious, GIT-related, and could be managed easily. Leukopenia after CPO or azathioprine treatment was reported infrequently. Therefore, a repeated blood count is indicated for early detection in order to discontinue the drug. The most serious adverse reaction was CsA-nephrotoxicity, as reported in two patients (6.4\%); it can be prevented by repeated renal biopsy for early detection. Another study on CsA with steroids (37 cases) reported striae in 29.7\%, hypertrichosis in $24.3 \%$, gingival hyperplasia in $13.5 \%$, and cataract in $8.1 \%$. CsA and MMF (23 cases) reported diarrhea in $13.0 \%$, abdominal pain in $17.4 \%$, and mild anemia in $13.0 \%$ (26). From the analysis of this work compared to the published studies, one can notice similarities and differences between the reported data, and this may be explained as many of the studies are non-randomized, include a small number of cases, and lack control groups.

\section{Conclusions}

The high potency of cyclosporine A with steroids recommends its use in patients with idiopathic SRNS provided they have a normal glomerular filtration rate. Its efficacy is further augmented when combined with MMF. This allows the weaning of patients from CsA after induction of remission, keeping them on MMF and low-dose steroids only, thereby avoiding CsA-nephrotoxicity and dependence. Cyclophosphamide as six-monthly intravenous boluses or orally for three months together with alternate-day steroids could be a good option provided that the patient is not within the peripubertal age range. However, deficient pathological data and its infrequent use in the boluses form were limiting factors for its proper assessment. In FRNS and SDNS, outcome could be improved by encouraging compliance with the use of levamisole. Long-term studies as well as the exchange of multi-center data should be encouraged for continuous update of published recommendations and guidelines.

\section{Acknowledgments:}

The authors acknowledge all of the staff members of the unit who were involved in the care of the patients.

\section{Conflict of Interest:}

There is no conflict of interest to be declared.

\section{Authors' contributions:}

All authors contributed to this work and article equally. All authors read and approved the final manuscript.

\section{References}

1) Niaudet P, Boyer O. Idiopathic Nephrotic Syndrome in Children: Clinical Aspects. In: Avner ED, Harmon WE, Niaudet P, Yoshikawa N, editors. Pediatric Nephrology. 6th ed. Berlin Heidelberg: Springer-Verlag; 2009. p. 667-702. doi: 10.1007/978-3-540-76341-3_28.

2) Indian Society of Pediatric Nephrology, Gulati A, Bagga A, Gulati S, Mehta KP, Vijayakumar M. Management of Steroid resistant Nephrotic Syndrome. Indian Pediatr. 2009; 46(1): 35-47. PMID: 19179716.

3) Moustafa B. Mapping Pediatric Nephrology in Africa. First Congress of African Pediatric Nephrology Association (AFPNA), Cairo-Egypt, February 2000.

4) The primary nephrotic syndrome in children. Identification of patients with minimal change nephrotic syndrome from initial response to prednisone. A report of the international study of kidney disease in children. J Pediatr. 1981; 98(4): 561-4. doi: 10.1016/S0022-3476(81)80760-3. PMID: 7205481.

5) Teeninga N, Kist-van Holthe JE, van Rijswijk N, de Mos NI, Hop WC, Wetzels JF, et al. Extending prednisolone treatment does not reduce relapses in childhood nephrotic syndrome. J Am Soc Nephrol. 2013; 24(1): 149-59. doi: 10.1681/ASN.2012070646. PMID: 23274956 , PMCID: PMC3537218.

6) AlSalloum AA, Muthanna A, Bassrawi R, Al Shehab AA, Al Ibrahim A, Islam MZ, et al. Long-term outcome of the difficult nephrotic syndrome in children. Saudi J Kidney Dis Transpl. 2012; 23(5): 965-72. doi: 10.4103/1319-2442.100877, PMID: 22982908.

7) Kari JA, Halawani M, Mokhtar G, Jalalah SM, Anshasi W. Pattern of steroid resistant nephrotic syndrome in children living in the kingdom of Saudi Arabia. Saudi J Kidney Dis Transpl. 2009; 20(5): 854-57. PMID: 19736491.

8) Nephrotic syndrome in children: prediction of histopathology from clinical and laboratory characteristics at time of diagnosis. A report of the International Study of Kidney Disease in Children. Kidney Int. 1978: 13(2): 159-65. doi: 10.1038/ki.1978.23, PMID: 713276. 
9) Gipson DS, Massengill SF, Yao L, Nagaraj S, Smoyer WE, Mahan JD, et al. Management of childhood onset nephrotic syndrome. Pediatrics. 2009; 124(2): 747-57. doi: 10.1542/peds.2008-1559, PMID: 19651590.

10) Chesney R. The changing face of childhood nephrotic syndrome. Kidney Int. 2004; 66(3): 1294-302. doi: 10.1111/j.1523/1755.2004.00885.x, PMID: 15327442 .

11) Mekahli D, Liutkus A, Ranchin B, Yu A, Bessenay L, Girardin E, et al. Long-term outcome of idiopathic steroid-resistant nephrotic syndrome: a multicenter study. Pediatr Nephrol. 2009; 24(8): 1525-32. doi: 10.1007/s00467-009-1138-5, PMID: 19280229.

12) Anochie I, Eke F, Okpere A. Childhood nephrotic syndrome change in pattern and response to steroids. J Natl Med Assoc. 2006; 98(12): 1977-81. PMID: 17225845, PMCID: PMC2569667.

13) Coppo R. Non-steroidal and non-cytotoxic therapies for nephrotic syndrome. Nephrol Dial Transplant. 2008; 23(6): 1793-6. doi: 10.1093/ndt/gfn211, PMID: 18441003.

14) Peña A, Bravo J, Melgosa M, Fernandez C, Meseguer C, Espinosa L, et al. Steroid-resistant nephrotic syndrome: long-term evolutionafter sequential therapy. Pediatr Nephrol. 2007; 22(11): 1875-80. doi: 10.1007/s00467-007-0567-2, PMID: 17876609.

15) Banaszak B, Banaszak P. The increasing incidence of initial steroid resistance in childhood nephrotic syndrome. Pediatr Nephrol. 2012; 27(6): 927-32. doi: 10.1007/s00467-011-2083-7, PMID: 22231438, PMCID: PMC3337414.

16) Bagga A. Revised guidelines for management of steroid-sensitive nephrotic syndrome. Indian $J$ Nephrol. 2008; 18(1): 31-9. doi: 10.4103/0971-4065.41289, PMCID: PMC2847730.

17) Zagury A, Oliveira AL, Montalvão JA, Novaes RH, Sá VM, Moraes CA, et al. Steroid-resistant idiopathic nephrotic syndrome in children: long-term follow-up and risk factors for end-stage renal disease. J Bras Nefrol. 2013; 35(3): 191-9. doi: 10.5935/0101-2800.20130031, PMID: 24100738.

18) Iyengar A, Karthik S, Kumar A, Biswas S, Phadke K. Cyclosporine in steroid dependent and resistant childhood nephrotic syndrome. Indian Pediatr. 2006; 43(1): 14-9. PMID: 16465001.

19) Ekambaram S, Mahalingam V, Nageswaran P, Udani A, Geminiganesan S, Priyadarshini S. Efficacy of levamisole in children with frequently relapsing and steroid-dependent nephrotic syndrome. Indian Pediatr. 2014; 51(5): 371-3. doi: 10.1007/s13312-014-0419-7. PMID: 24953577.

20) Gipson DS, Chin H, Presler TP, Jennette C, Ferris ME, Massengill S, et al. Differential risk of remission and ESRD in childhood FSGS. Pediatr Nephrol. 2006: 21(3): 344-9. doi: 10.1007/s00467/005/2097/0. PMID: 16395603.

21) Cattran DC, Wang MM, Appel G, Matalon A, Briggs W. Mycophenolatemofetil in the treatment of focal segmental glomerulosclerosis. Clin Nephrol. 2004; 62(6): 405-11. doi: 10.5414/CNP62405. PMID: 15630898.

22) Brandis M, Burghard R, Leititis J, Zimmerhackl B, Hildebrandt F, Helmchen U. Cyclosporine A for treatment of nephrotic syndrome. Transplant Proc. 1988; 20(3 Suppl 4): 275-9. PMID: 3381283.

23) Niaudet P. Treatment of childhood steroid-resistant idiopathic nephrosis with a combination of cyclosporine and prednisone. French Society of Pediatric Nephrology. J Pediatr. 1994; 125(6 Pt 1): $981-6$. doi: 10.1016/S0022-3476(05)82020-7. PMID: 7996374.

24) Echeverri CV, Valencia GA, Higuita LM, GayuboAK, Ochoa CL, Rosas LF, et al. Immunosupressive therapy in children with steroid-resistant nephrotic syndrome: single center experience. J Bras Nefrol. 2013; 35(3): 200-5. doi: 10.5935/0101-2800.20130032, PMID: 24100739.

25) Ulinski T, Dubourg L, Saïd MH, Parchoux B, Ranchin B, Cochat P. Switch from cyclosporine A to mycophenolatemofetil in nephrotic children. Pediatr Nephrol. 2005; 20: 482-5. doi: 10.1007/s00467/004/1778/4, PMID: 15719253.

26) Nikibakhsh AA, Mahmoodzadeh H, Karamyyar M, Hejazi S, Noroozi M, Macooie AA. Treatment of steroid and cyclosporine-resistant idiopathic nephrotic syndrome in children. Int J Nephrol. 2011; 2011: 930965. doi: 10.4061/2011/930965, PMID: 21949905.

27) Kari JA, Halawani M. Treatment of steroid resistant nephrotic syndrome in children. Saudi J kidney Dis Transpl. 2010; 21(3): 484-7. PMID: 20427873.

28) Siegel NI, Gur A, Krassner LS, Kashgarian M. Minimal-lesion nephrotic syndrome with early resistance to steroid therapy. J Pediatr. 1975; 87(3): 377-80. PMID: 1165516.

29) Cameron JS, Turner DR, Ogg CS, Sharpstone P, Brown CB. The nephrotic syndrome in adults with 'minimal change' glomerular lesions. Q J Med. 1974; 43(171): 461-88. PMID: 4422336. 
30) Tejani A, Phadke K, Nicastri A, Adamson O, Chen CK, Trachtman H, et al. Efficacy of cyclophosphamide in steroid-sensitive childhood nephrotic syndrome with different morphological lesions. Nephron. 1985; 41(2): 170-3. PMID: 4047274.

31) Bajpai A, Bagga A, Hari P, Dinda A, Srivastava RN. Intravenous cyclophosphamide in steroid-resistant nephrotic syndrome. Pediatr Nephrol. 2003; 18(4): 351-6. PMID: 12700961.

32) Madani A, Isfahani ST, Rahimzadeh N, Fereshtehnejad SM, Hoseini R, Moghtaderi M, et al. Effect of levamisole in steroid-dependent nephrotic syndrome. Iran J Kidney Dis. 2010; 4(4): 292-6. PMID: 20852369.

33) Levamisole for corticosteroid-dependent nephrotic syndrome in childhood. British Association for Paediatric Nephrology. Lancet. 1991; 337(8757): 1555-7. PMID: 1675705.

34) Barratt TM, Soothill JF. Controlled trial of cyclophosphamide in steroid-sensitive relapsing nephrotic syndrome of childhood. Lancet. 1970; 2(7671): 479-82. doi: 10.1016/S0140/6736(70)90108-8. PMID: 4194935.

35) Chen SY, Wu CY, Tsai IJ, Tsau YK. Treatment course of steroid-dependent nephrotic syndrome: emphasized on treatment effect. Nephrology. 2010; 15(3): 336-9. doi: 10.1111/j.1440-1797.2009.01190.x. PMID: 20470303.

36) Ueda N, Kuno K, Ito S. Eight and 12 week courses of cyclophosphamide in nephrotic syndrome. Arch Dis Child. 1990; 65(10): 1147-50. PMID: 2248508, PMCID: PMC1792340.

37) Kyrieleis HA, Levtchenko EN, Wetzels JF. Long-term outcome after cyclophosphamide treatment in children with steroid dependent and frequently relapsing minimal change nephrotic syndrome. Am J Kidney Dis. 2007; 49(5): 592-7. PMID: 17472840.

38) Durkan AM, HodsonEM, Willis NS, Craig JC. Immunosuppressive agents in childhood nephrotic syndrome: a meta-analysis of randomized controlled trials. Kidney Int. 2001; 59(5): 1919-27. doi: 10.1046/j.1523/1755.2001. 0590051919.x, PMID: 11318964. 